Robert L. Glover, MD

Lauren V. DeNiro, MD

Patrick A. Lasala, MD

Karen M. Weidenheim, $\mathrm{MD}$

Jerome J. Graber, MD

Alexis Boro, MD

Correspondence to

Dr. Glover:

rglover@montefiore.org

\title{
ILAE type 3 hippocampal sclerosis in patients with anti-GAD-related epilepsy OPEN
}

\section{ABSTRACT}

Objective: To describe the neuropathologic findings and clinical course of 2 patients who underwent temporal lobectomy for medically refractive epilepsy and were later found to have high anti-glutamic acid decarboxylase (GAD) concentrations.

Methods: Small case series.

Results: Neuropathologic examination of both patients revealed International League Against Epilepsy (ILAE) type 3 hippocampal sclerosis. Following surgery, both developed signs and symptoms of stiff person syndrome and later cerebellar ataxia. Laboratory studies demonstrated high concentrations of anti-GAD antibodies in both patients.

Conclusions: These cases suggest that ILAE type 3 hippocampal sclerosis may be immunologically related to and may exist as part of a broader anti-GAD-related neurologic syndrome in some instances. Neurol Neuroimmunol Neuroinflamm 2015;2:e122; doi: 10.1212/NXI.0000000000000122

\section{GLOSSARY}

GAD = glutamic acid decarboxylase; HS = hippocampal sclerosis; ILAE = International League Against Epilepsy; IVIg = IV immunoglobulin; SPS = stiff person syndrome; TLE = temporal lobe epilepsy.

Autoantibodies to glutamic acid decarboxylase (GAD) are associated with a host of neurologic conditions, including stiff person syndrome (SPS), autoimmune cerebellar ataxia, and autoimmune-mediated epilepsies, as well as type 1 diabetes mellitus. ${ }^{1}$ Although initially described as distinct entities, it is increasingly recognized that a subset of patients evolve within and simultaneously exhibit a range of the neurologic manifestations in the spectrum of antiGAD-related presentations. ${ }^{2}$ At the same time, little is known about the mechanisms of antiGAD-related neuropathology in general or about the substrates of anti-GAD-related epilepsy in particular. We present 2 patients with high concentrations of anti-GAD antibodies who underwent resective surgery for medically intractable temporal lobe epilepsy (TLE) with hippocampal sclerosis (HS) and subsequently developed SPS and later cerebellar ataxia. TLE is the most common form of medically intractable epilepsy in adults, and resective surgery is the most effective therapy for appropriately selected patients with medically intractable focal epilepsy. ${ }^{3}$ The most common form of HS (International League Against Epilepsy [ILAE] type 1) is characterized by cell loss in CA1 and CA4 regions. These patients typically have an early age of seizure onset and a history of febrile seizures. ${ }^{4}$ Our patients demonstrated ILAE type 3 HS or "end folium sclerosis," the least common form, representing just 5 of 165 surgical resections in one study. ${ }^{5}$ Patients with this form of HS typically develop epilepsy at a later age, often in the absence of an initial precipitating injury or identifiable etiology. ${ }^{6}$ These cases provide insight into the neuropathologic signatures that may be associated with presumptive anti-GAD-related epilepsy.

\footnotetext{
From the Department of Neurology (R.L.G., L.V.D., K.M.W., J.J.G., A.B.), Department of Neurological Surgery (P.A.L., K.M.W.), and Department of Pathology (K.M.W.), Albert Einstein College of Medicine, Montefiore Medical Center, Bronx, NY. Funding information and disclosures are provided at the end of the article. Go to Neurology.org/nn for full disclosure forms. The Article Processing Charge was paid by the authors. This is an open access article distributed under the terms of the Creative Commons Attribution-NonCommercial-NoDerivatives License 4.0 (CC
BY-NC-ND), which permits downloading and sharing the work provided it is properly cited. The work cannot be changed in any way or used This is an open access article distributed under the terms of the Creative Commons Attribution-NonCommercial-NoDerivatives License 4.0 (CC
BY-NC-ND), which permits downloading and sharing the work provided it is properly cited. The work cannot be changed in any way or used commercially.
} 
CASE REPORTS Case 1. A 28-year-old woman developed intractable seizures at the age of 18. Initial MRI showed decreased volume in the left hippocampus without signal abnormality and abnormal T2 signal in the right hippocampus without volume loss. Wada test scores were 5/5 using the left hemisphere (right carotid injection) and 3/5 using the right hemisphere. At the age of 21, she underwent invasive EEG monitoring, which captured 10 seizures arising from the right hippocampus and 1 from the left. She underwent right amygdalohippocampectomy. Surgical pathology demonstrated ILAE type 3 HS (figure 1). Convulsive seizures resolved with surgery, but both complex partial seizures and nonepileptic events continued.

At the age of 24, she began to have gait difficulties with mild leg stiffness. Two years later left arm dysmetria and gait ataxia become prominent, consistent with cerebellar dysfunction. Her anti-GAD level was found to be greater than $300 \mathrm{U} / \mathrm{mL}$ (radioimmunoassay, normal range 0-1.1). CSF studies showed oligoclonal bands and an $\mathrm{IgG/total}$ protein ratio of 0.01 but were otherwise normal. There was no evidence of other organ-specific autoimmune disease. She was diagnosed with concomitant SPS and cerebellar ataxia. She is now on regular IV immunoglobulin (IVIg) infusions with mild improvement in gait.
Plasma exchange therapy did not result in additional clinical benefit.

Case 2. A 31-year-old man developed complex partial seizures at the age of 22. Serial MRI studies showed progressive left hippocampal atrophy and signal abnormality. His seizures rapidly became intractable to medical therapy. Memory performances on Wada testing were nonlateralizing. He underwent a left temporal lobectomy at the age of 29. Invasive monitoring was done because of concern that the seizure onset zone was neocortical. The initial ictal EEG changes were detected in perihippocampal depth contacts. He underwent left amygdalohippocampectomy. He has been completely free of seizures since. Surgical pathology demonstrated ILAE type 3 HS (figure 2). Immunohistochemical studies using antibodies for $\mathrm{T}$ cells (CD3), $\mathrm{T}$ cell subsets (CD4 and CD8), B lymphocytes (CD20), plasma cells (CD138), and granzyme were performed and did not reveal lymphocytes or plasma cells in the parenchyma or subarachnoid space.

Five months after surgery, he began to report stiffness and spasms of the back. On examination at that time, he was found to have increased muscle tone in the lower extremities and myoclonic jerks. Findings later included gaze-evoked diplopia and respiratory

Figure 1 Case 1
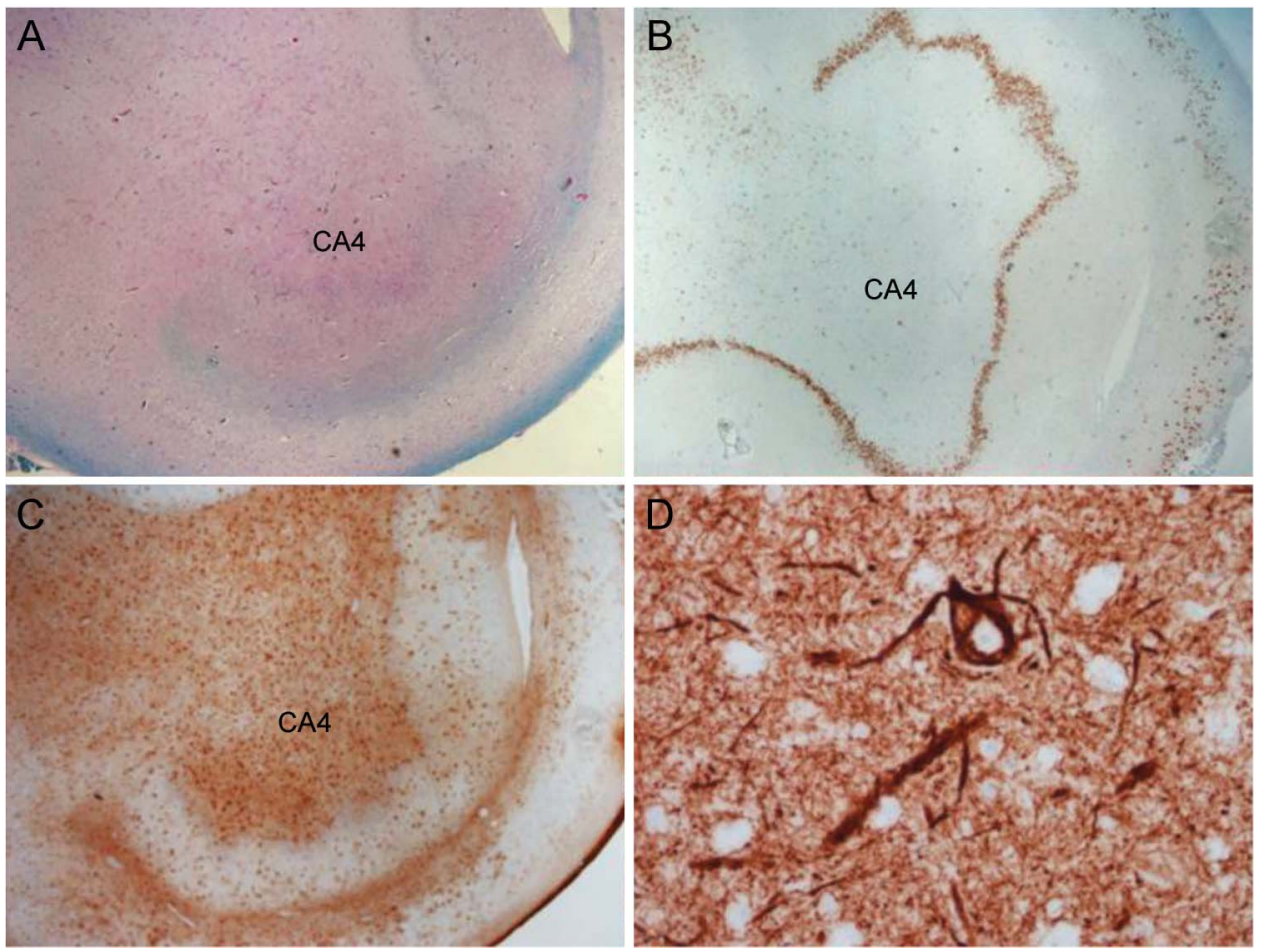

(A) Section stained with Luxol fast blue for orientation (original magnification $\times 20$ ). (B) A NeuN immunohistochemical preparation reveals very few brown-stained neurons in CA4. (C) Immunohistochemistry for astrocytes using glial fibrillary acidic protein shows gliosis (original magnification $\times 20$ ). (D) A dysplastic neuron expressing neurofilament protein from CA4 (original magnification $\times 400$ ). 

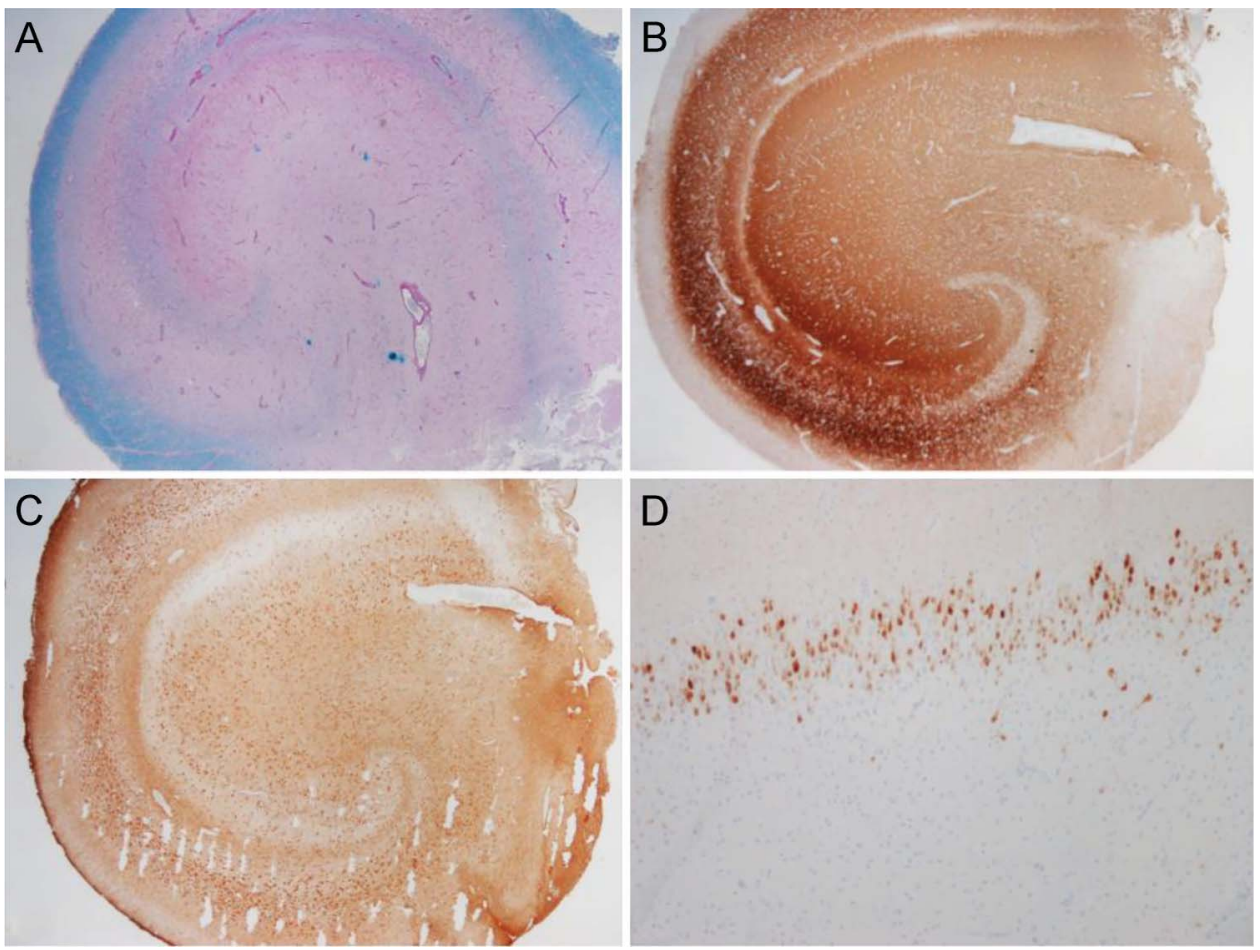

(A) Section stained with Luxol fast blue for orientation; CA4 is seen in the center between the blades of the fascia dentata (original magnification $\times 20$ ). (B) Synaptophysin staining is well preserved. (C) Gliosis was noted in CA4 corresponding to the neuronal loss. This is the pattern of end folium sclerosis. (D) High-power (original magnification $\times 200$ ) view of the fascia dentata showing dispersion and migration of neurons stained with NeuN.

dysfunction due to stiffness of the respiratory musculature. On laboratory testing, serum anti-GAD level was found to be greater than $300 \mathrm{U} / \mathrm{mL}$. Anti-thyroglobulin, anti-thyroid peroxidase, and anti-parietal cell antibodies were also present. EMG studies demonstrated continuous motor unit activity. He was diagnosed with SPS, which improved with IVIg and methylprednisolone. Approximately 3 years after surgery, he developed a cerebellar syndrome with speech changes, diplopia, dysmetria, and ataxia. These symptoms also responded to pulsed steroid treatments and IVIg.

DISCUSSION We describe 2 patients who initially presented with medically refractory TLE due to ILAE type $3 \mathrm{HS}$, were found to have high levels of antiGAD antibodies, and later developed SPS and cerebellar syndromes. One of the patients remains free of seizures after temporal lobectomy; the other continues to have seizures, the frequency of which has not clearly been altered by immune modulatory treatment. However, in both patients, SPS and cerebellar syndromes did respond to immune modulatory treatment.

The association of seizures with anti-GAD autoantibodies has been previously described. High GAD antibody levels were found in $2.8 \%$ of patients with epilepsy in a recent study that included patients with both well-controlled and uncontrolled epilepsy.7,8 ILAE type $3 \mathrm{HS}$ has been described in a small number of specimens from other patients with presumed autoimmune-related epilepsy, including a patient with suspected anti-GAD-related limbic encephalitis. ${ }^{4,9}$ Bien et al. ${ }^{10}$ described pathologic specimens from 3 patients with anti-GAD encephalitis in which there was no immunoglobulin or complement deposition, arguing against an antibody-mediated mechanism. On the other hand, markers of a $\mathrm{T}$ cell-mediated cytotoxic process, while present, reflected less-intense activation than that seen in other forms of autoimmune encephalitis due to intracellular antigens. ${ }^{10}$ The rarity of ILAE type $3 \mathrm{HS}$ and the overlap between the pathologic findings in these cases and previously published descriptions of specimens from patients with anti-GAD-related epilepsy strongly suggest that anti-GAD antibodies underlie these patients' epilepsy and SPS with cerebellar ataxia.

The cases described here contribute to our understanding of the phenomenon of anti-GAD-related epilepsy in 2 ways. First, they illustrate the evolution of anti-GAD-related neurologic syndromes from epilepsy to other branches of the condition, which has been less well-described than transitions and overlaps between SPS and cerebellar syndromes. Second, there 
are few descriptions of pathologic specimens from patients with TLE and anti-GAD antibodies. These 2 cases strengthen the hypothesis of an association between anti-GAD antibodies and some cases of ILAE type 3 HS. The pathophysiology of antiGAD-associated autoimmune disorders remains unknown. ${ }^{1}$ Our specimens did not show any evidence of a cytotoxic response. They were obtained late in the course of the development of the epilepsy, leaving open the possibility of cytotoxic processes. The other neurologic manifestations of anti-GAD_ related autoimmunity, however, developed after these specimens were obtained. Similar to the cases described by Bien et al., ${ }^{10}$ the presence of oligoclonal bands in case 1 and anti-thyroid and anti-parietal antibodies in case 2 suggests a possible role for antibody-mediated mechanisms. If an antibodymediated process is relevant in these cases, it is unclear whether anti-GAD antibodies themselves or coexisting antibodies to an unknown antigen are pathogenic. $^{10}$

Although a small sample, these cases suggest that ILAE type $3 \mathrm{HS}$ may be immunologically mediated in some cases and that TLE due to ILAE type 3 HS may be one component of a broader anti-GAD related neurologic syndrome in some patients. If there is a unifying explanation of the mechanisms of antiGAD-related neuropathology, these cases suggest that hypotheses will have to accommodate the development of HS, SPS, and cerebellar dysfunction in the same patient.

\section{AUTHOR CONTRIBUTIONS}

Dr. Robert Glover worked on manuscript drafting, editing, and image editing. Dr. Lauren DeNiro worked on manuscript drafting and editing. Dr. Patrick Lasala proofread and edited the document for content, particularly regarding the neurosurgical details. Dr. Karen Weidenheim worked on manuscript drafting, pathologic analysis, and image acquisition. Dr. Jerome Graber worked on manuscript drafting and editing. Dr. Alexis Boro worked as senior author and oversaw all drafting and editing.

\section{STUDY FUNDING}

No targeted funding reported.

\section{DISCLOSURE}

R.L. Glover, L.V. DeNiro, P.A. Lasala, and K.M. Weidenheim report no disclosures. J.J. Graber serves on a scientific advisory board for Novacure, Inc. and a data safety monitoring board for Stemedica, Inc., was formerly on a speakers' bureau for Biogen Idec, and received research support from Diogenix, Novartis, Biogen, and Radiation Therapy Oncology Group. A. Boro reports no disclosures. Go to Neurology.org/nn for full disclosure forms.

Received February 7, 2015. Accepted in final form May 5, 2015.

\section{REFERENCES}

1. Alexopoulos H, Dalakas MC. Immunology of stiff person syndrome and other GAD-associated neurological disorders. Expert Rev Clin Immunol 2013;9: 1043-1053.

2. Georgieva Z, Parton M. Cerebellar ataxia and epilepsy with anti-GAD antibodies: treatment with IVIG and plasmapheresis. BMJ Case Rep 2014; doi: 10.1136/ bcr-2013-202314.

3. Wiebe S, Blume WT, Girvin JP, Eliasziw M; Effectiveness and Efficiency of Surgery for Temporal Lobe Epilepsy Study Group. A randomized, controlled trial of surgery for temporal-lobe epilepsy. N Engl J Med 2001;345: 311-318.

4. Blümcke I, Thom M, Aronica E, et al. International consensus classification of hippocampal sclerosis in temporal lobe epilepsy: a Task Force report from the ILAE Commission on Diagnostic Methods. Epilepsia 2013;54: 1315-1329.

5. Thom M, Liagjouras I, Elliot KJ, et al. Reliability of patterns of hippocampal sclerosis as predictors of postsurgical outcome. Epilepsia 2010;51:1801-1808.

6. Blümcke I, Pauli E, Clusmann $\mathrm{H}$, et al. A new clinicopathological classification system for mesial temporal sclerosis. Acta Neuropathol 2007;113:235-244.

7. Davis R, Dalmau J. Autoimmunity, seizures, and status epilepticus. Epilepsia 2013;54(suppl 6):46-49.

8. Falip M, Carreno M, Miro J, et al. Prevalence and immunological spectrum of temporal lobe epilepsy with glutamic acid decarboxylase antibodies. Eur J Neurol 2012;19: 827-833.

9. Malter MP, Helmstaedter C, Urbach $\mathrm{H}$, Vincent A, Bien CG. Antibodies to glutamic acid decarboxylase define a form of limbic encephalitis. Ann Neurol 2010;67:470-478.

10. Bien CG, Vincent A, Barnett MH, et al. Immunopathology of autoantibody-associated encephalitides: clues for pathogenesis. Brain 2012;135:1622-1638. 


\title{
Neurology $^{\odot}$ \\ Neuroimmunology \& Neuroinflammation
}

\author{
ILAE type 3 hippocampal sclerosis in patients with anti-GAD-related epilepsy \\ Robert L. Glover, Lauren V. DeNiro, Patrick A. Lasala, et al. \\ Neurol Neuroimmunol Neuroinflamm 2015;2; \\ DOI 10.1212/NXI.0000000000000122
}

This information is current as of June 25, 2015

\section{Updated Information \& Services}

References

Subspecialty Collections

Permissions \& Licensing

Reprints including high resolution figures, can be found at:

http://nn.neurology.org/content/2/4/e122.full.html

This article cites 9 articles, 0 of which you can access for free at: http://nn.neurology.org/content/2/4/e122.full.html\#\#ref-list-1

This article, along with others on similar topics, appears in the following collection(s):

Autoimmune diseases

http://nn.neurology.org//cgi/collection/autoimmune_diseases

Epilepsy surgery

http://nn.neurology.org//cgi/collection/epilepsy_surgery_

Gait disorders/ataxia

http://nn.neurology.org//cgi/collection/gait_disorders_ataxia

Hippocampal sclerosis

http://nn.neurology.org//cgi/collection/hippocampal_sclerosis

Stiff person syndrome

http://nn.neurology.org//cgi/collection/stiff_person_syndrome

Information about reproducing this article in parts (figures,tables) or in its entirety can be found online at:

http://nn.neurology.org/misc/about.xhtml\#permissions

Information about ordering reprints can be found online:

http://nn.neurology.org/misc/addir.xhtml\#reprintsus

Neurol Neuroimmunol Neuroinflamm is an official journal of the American Academy of Neurology.

Published since April 2014, it is an open-access, online-only, continuous publication journal. Copyright $\odot$ 2015 American Academy of Neurology. All rights reserved. Online ISSN: 2332-7812.

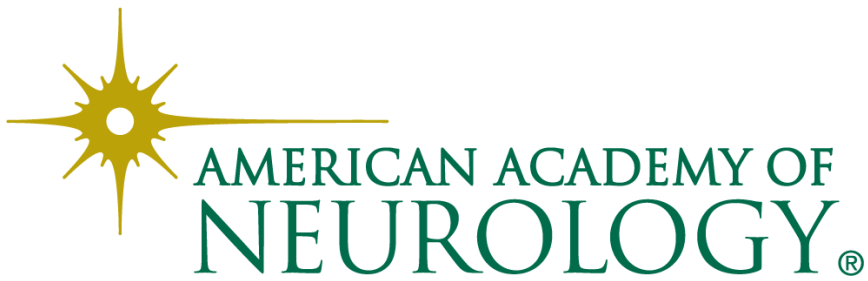

